Opinion Section

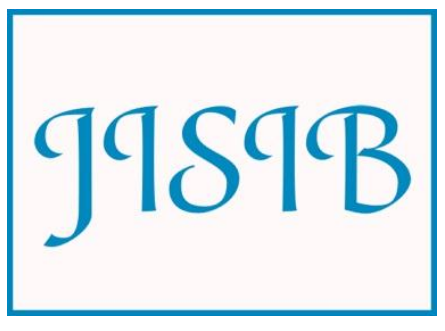

Available for free online at https://ojs.hh.se/

Journal of Intelligence Studies in Business Vol 4, No 1 (2014) 26-35

\title{
Competitive Intelligence cycle in the light of web 2.0 tools
}

\author{
Luc Quoniam ${ }^{1}$ and Charles-Victor Boutet ${ }^{2}$ \\ ${ }^{1}$ Laboratoire Paragraphe, Université Paris VIII, France \\ ${ }^{2}$ UFR Ingémedia, USTV, France \\ Email: mail@quoniam.info, mnem00@gmail.com
}

Received September 3 2013, accepted February 9, 2014

\begin{abstract}
We propose in this study, detailing our observations and research on the impact of the web 2.0, its associated tools, the cycle of the economic intelligence with new paradigms such as the many-to-many, new practices such as active SEO allow any individual, firm, to impact heavily on the aforementioned round, both in terms of information circulation, as data collection.
\end{abstract}

KEYWORDS: Competitive Intelligence, Web 2.0, Intelligence Cycle,

\section{Introduction}

The information cycle in Figure 1 (or intelligence, or competitive intelligence system) is a central landmark in economic intelligence. It is most often represented in a series of stages from planning needs to information diffusion, steps that will refine raw information into intelligence (Dedijer, 1999). The information as such is a raw material. Refined (integrated / assimilated by the subject), it becomes knowledge (Stenmark, 2002)
(Skryme, 2000) (Davenport, 1997). It is from this model that the cycle of information has been developed in the cycle which information is collected, organized, transmitted, evaluated, analyzed and made available to decision makers for inclusion in the decision making as shown in Figure 1. 


\section{Opinion Section}

However, in recent years Internet 2.0 has spread: everyone can now easily create his own virtual territory composed of everything from one to thousands of sites, and virtually all the territories are considered to be participatory: everyone can write, promote his or her site (Boutet and Ben Amor, 2010). The many-to-many model allows for wide dissemination of information for everyone and enables SEO 2.0, whose heart activity is based on tools for mass application, allows, besides a better ranking, an echo globally as shown in Figure 2, a de-facto better visibility. This participatory paradigm shift has prompted us to revisit the cycle in light of the aforementioned tools 2.0.

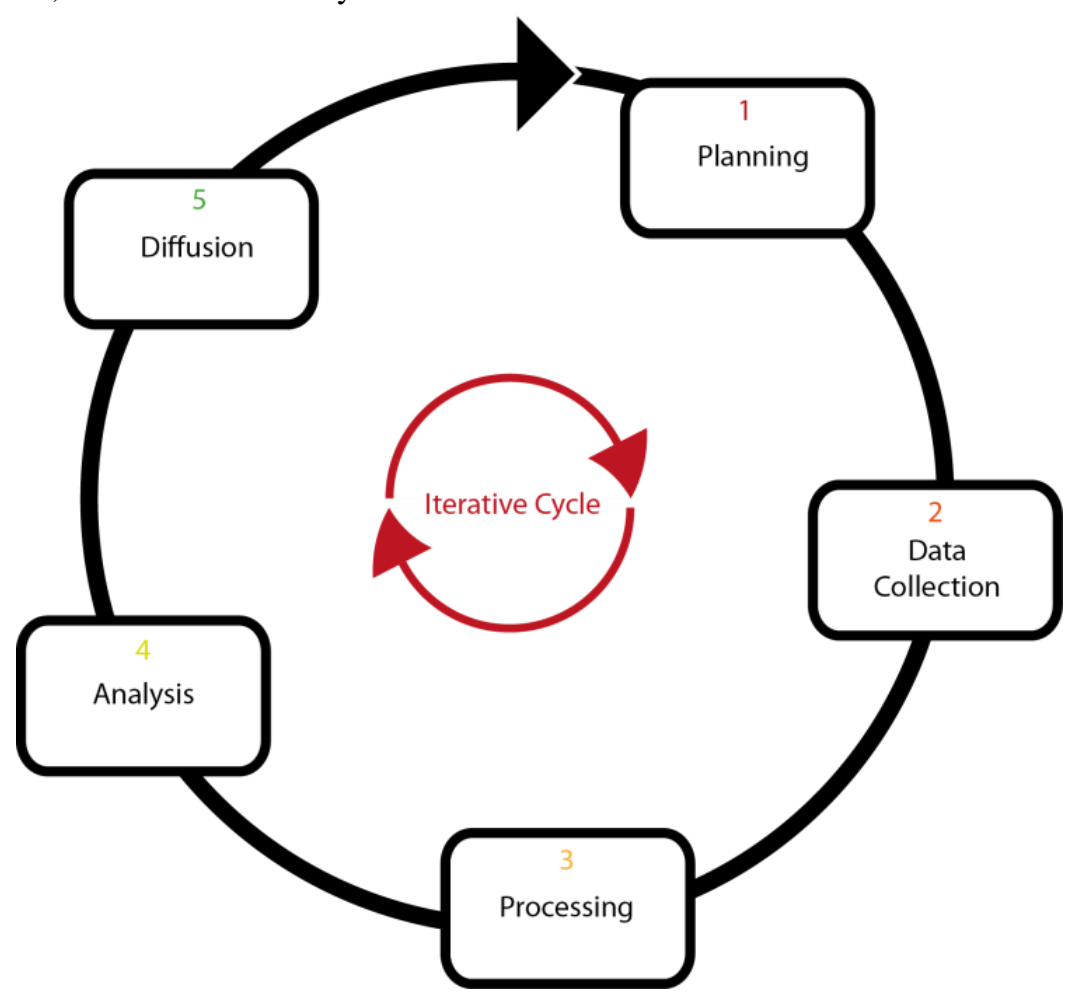

Figure 1. Informational approach of the intelligence cycle

\subsection{Dissemination and active SEO 2.0:}

For clarity, we will refer to the concept of "2.0" as the broad consequence of a disruption technically very simple: rules for authorizing access to information systems: Internet, formerly ARPANET, was created to across UNIX systems and related products, and network architecture was (and still is) together with the software architecture of such systems. In this context, any resource is subject to access rights: Read, Write and Execute (RWX). Until the age of 2.0 (also known as writable web), the right to write access, which allows scientists to post comments on the weblog of an unknown, was strictly controlled as regards the web, simply prohibited. Since then, the norm is participatory and circulation of information: every internet user has the possibility of transmitting information, and with the right tools, engage in mass distribution.

- automation by creating a constellation of linked websites, the user provides Internet users a vast window on the information he wants to communicate

- communicating information is through automation on a variety of media allowing writing (blogs, forums, social bookmarking sites ...) as shown in Figure 3. 


\section{Opinion Section}

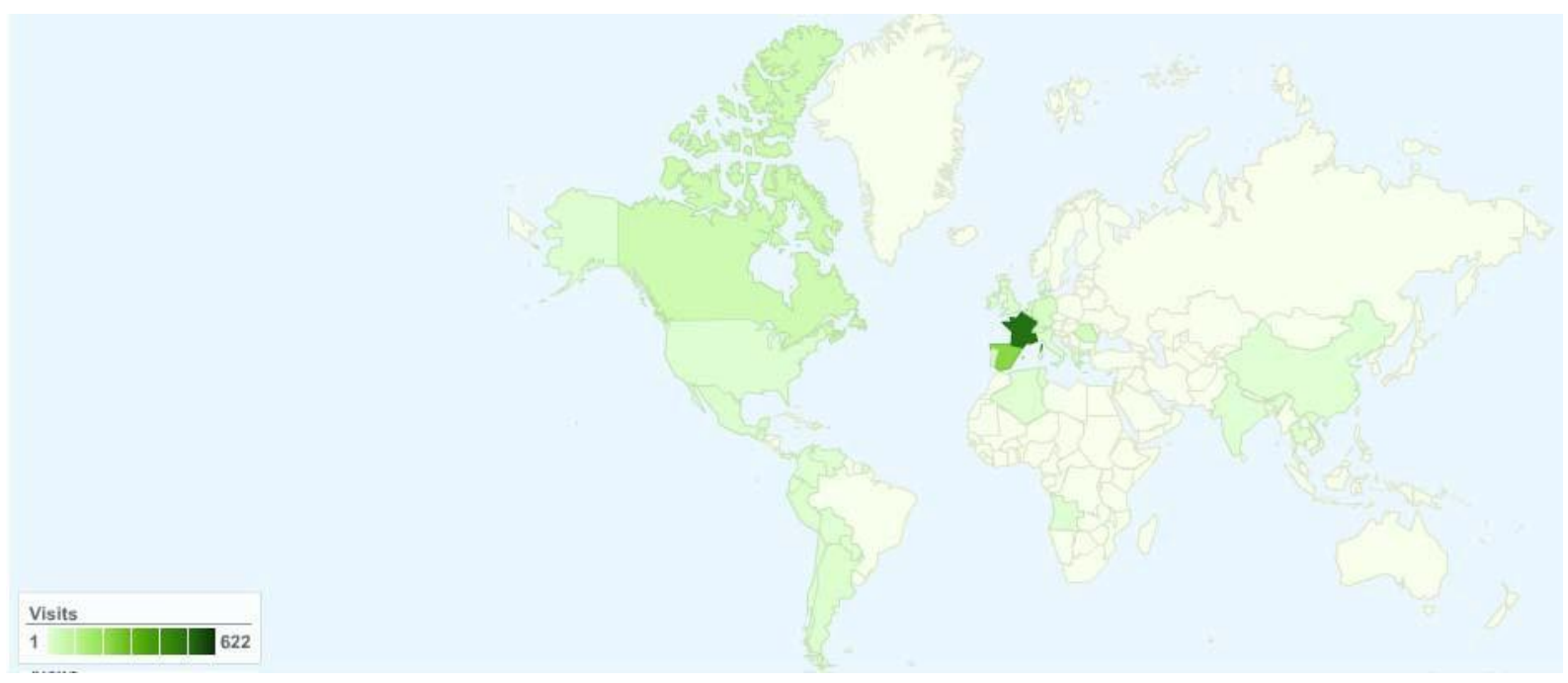

Figure 2. Geographical Visualization of global sources of visitors to the nutrisaveurs website after an Hispanic, Anglophone and Francophone active SEO campaign. The intensity of green color is proportional to the number of visits per territory.

\section{Glocadata harvesting}

The Web is a system originally designed for information management (Voss, 2007). Its system of full text automatic indexation (e.g. Google PageRank) has certain advantages. That said, in recent years, the manual indexing based on tags: folksonomies, has known a great success. This stigmergic ${ }^{1}$ process characterizes a collective intelligence leading to the marking of web pages with specific keywords, marking supposedly handmade synonymous with high congruence between the marked page and tags that are affixed and therefore reliability. Glocalization on Internet apparent from the technical aspect of the writable web that leads to the emergence of such uses. In this sense, Web 2.0 gives users the ability to find, organize, share and create information in ways both personal is globally accessible (Martin, 2007). This phenomenon of glocalization therefore allows precise adaptability of web resources for the user and is a way for anyone who uses "active SEO", to allocate

\footnotetext{
${ }^{1}$ Stigmergy is a method of indirect communication in a self-organized emerging environment, where people communicate among themselves by changing their environment (Wikipedia).
}

the data it publishes, synchronously or not, other users efficiently as shown in Figure 2. 


\section{Opinion Section}

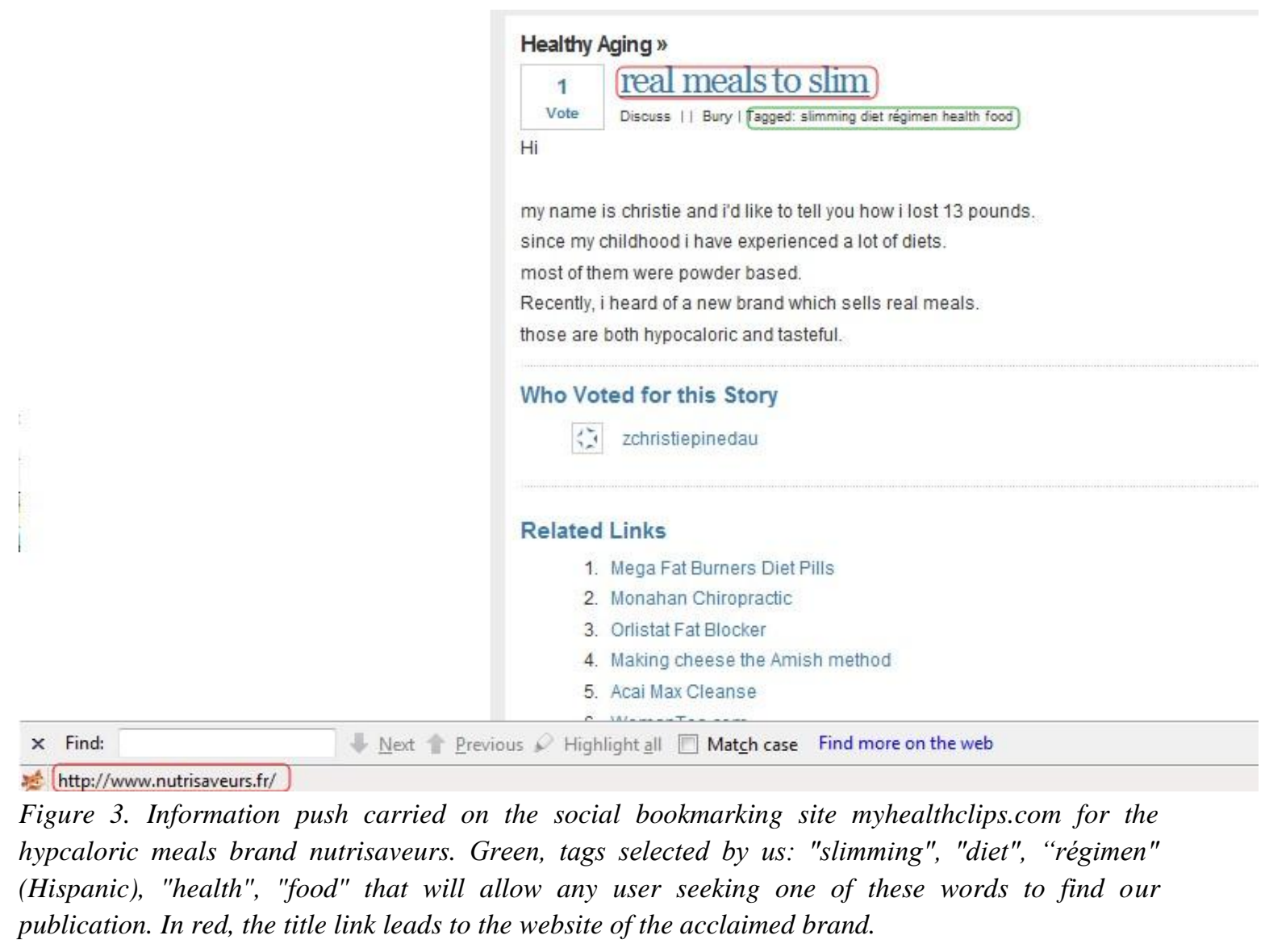

\subsection{Some implications on the intelligence cycle}

\subsection{Diffusion-collection impact:}

At first glance, one may think of this cycle as an intern to a structure or an organization. However, the possibility of mass dissemination of information from a company "A" by the means aforesaid will possibly impacting on the collection of data from companies $\mathrm{X}, \mathrm{Y}$ and $\mathrm{Z}$ such that illustrated in Figure 4.

\subsection{Lobbying by diffusion-collection impact:}

Visibility on the internet is a major issue because who is visible will generate traffic on a website of the reputation / legitimacy-about-to-one-keyword and sales. On the other hand, it is established that a surfer since cognitively limited in the act of searching through an engine, will restrict the navigation of some items among the first results given by the search engine (Loc. cit., Boutet and Ben Amor) (AT Internet Institute, 2009) (iProspect,
2006), it is important to be at the top of search results for a given keyword ${ }^{2}$. 2 Keyword: for a search engine, expression
composed of one or several words. 


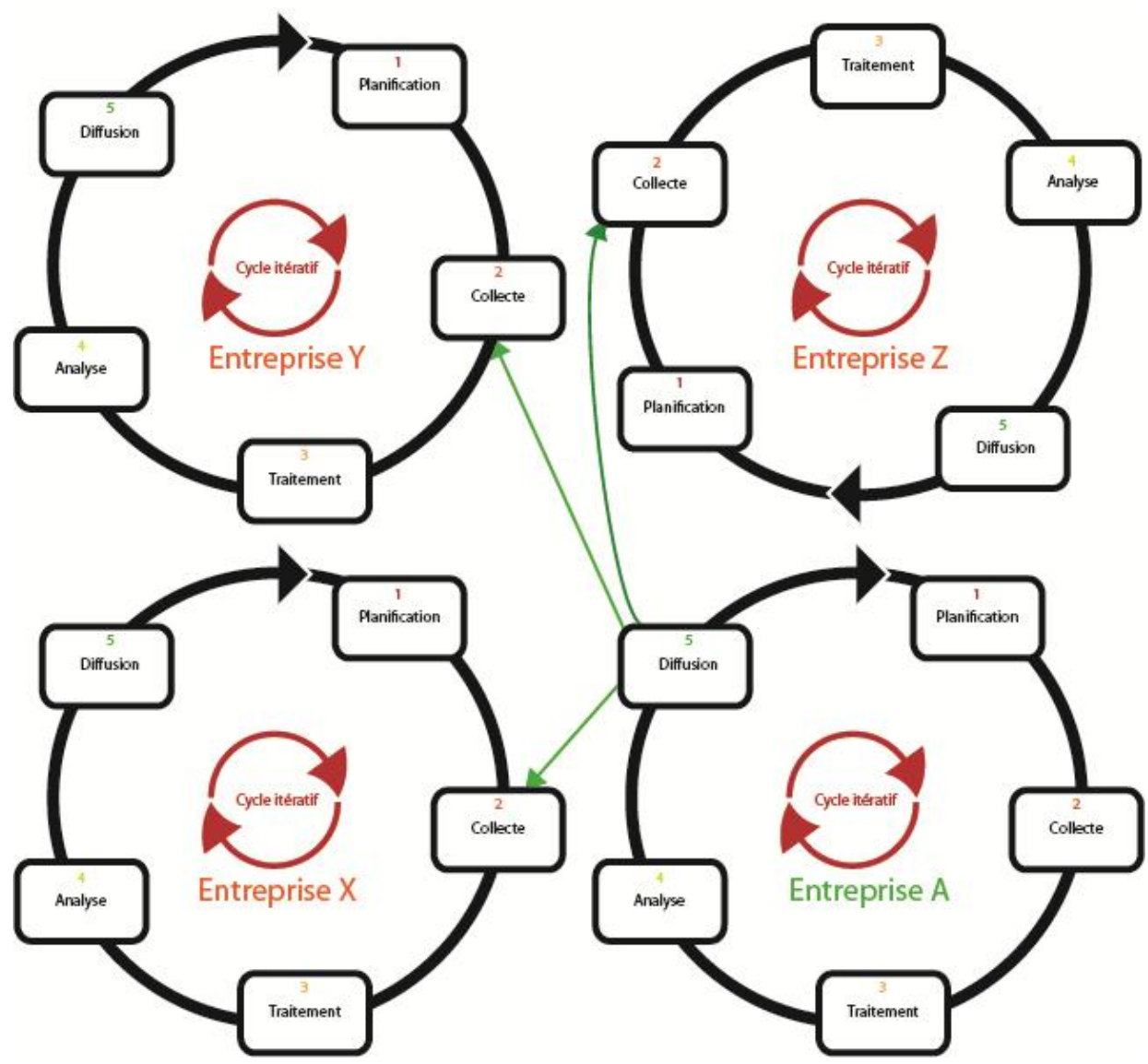

Figure 4. Synoptic view of the impact of the mass distribution of information on collecting through the prism of intelligence cycles of several companies

\subsection{1: Finding the right keyword}

To be visible on the internet, one must still find a keyword inherent in his heart craft capable of trafficking. On this point, Google offers "keywords tools" shown in Figure 5, which bases its results on one side past queries users collected through cookies that expire in the very long term to permit a grouping of keywords and the other on statistics compiled by the firm of Mountain View that quantify the research done on a keyword and to deduce the potential traffic obtained according to a geographical area and a target language for the website in the first position results following search criteria.

\subsection{2: competitive analysis on the chosen keyword}

Google sets its ranking following its famous algorithm: PageRank. If the latter is subject to a policy of opacity on the part of the firm, some parameters leading to a high ranking are notorious.
A number of the most important are in the module "SEO competition software market samurai", which provides a global view of competition on a certain keyword as shown in Figure 6.

The critical indicators include age of the domain name (DA Column), the pagerank (PR Column), the number of pages indexed by google for that area (IC column: index count) and finally the columns BLP (backlink page) and BLD (backlink domain), respectively the number of backlinks pointing to the page in this classification and those pointing to the domain name of this page. Given these results, it is possible to estimate whether a positioning among the top 10 (accessed by a majority of Internet users) is possible or not. Typically, a small number of backlinks from one of the top ten shows that we can reasonably expect to run for his spot, especially with us using the contributory aspect of Web 2.0. Indeed, we have the ability to post content including trackbacks (such <A http://www.mydomain.com> competitive 


\section{Opinion Section}

intelligence $</ a>$ ) that link to this site on any

media type 2.0

\begin{tabular}{|c|c|c|c|c|}
\hline [ Mot clé & Concurrence & Recherches mensulles globales (2) & Recherches mensuelles locales (2) & Tendances des recherches locales \\
\hline [t competitive intelligence & $\square$ & 33100 & 1000 & 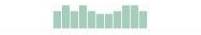 \\
\hline 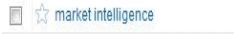 & $\|$ & 27100 & 720 & n|||||m||l| \\
\hline 國 chempetitive intelligence softuare & $\square$ & 880 & 46 & IIIIImemill|| \\
\hline [0 रु scip & $\square$ & 27100 & 1000 & 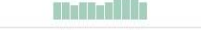 \\
\hline 圆 is marketing intelligence & $\square$ & 40500 & 1300 & ilithrillili \\
\hline 国 is intelligentbusiness & 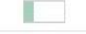 & 22200 & 590 & 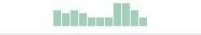 \\
\hline [1] software business intelligence & 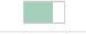 & 22200 & 210 & millimmillill \\
\hline [. fis strategic intelligence & $\square$ & 6600 & 210 & Millin_millilin \\
\hline [. th business intelligence services & $\square$ & 4400 & 140 & 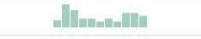 \\
\hline 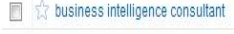 & $\square$ & 4400 & 320 & ||l||||m-n||||| \\
\hline 圆 biconsuttng & $\square$ & 2400 & 260 & ||lininil| \\
\hline 国 business intelligence solutions & 口 & 4400 & 210 & melntuminmillin \\
\hline 圆 business intelligence definition & $\square$ & 2400 & 140 & Allinen-milin \\
\hline 可 business intelligence consulting & $\square$ & 2400 & 58 & 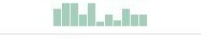 \\
\hline 國 bi bibusiness intelligence & $\square$ & 5400 & 140 & 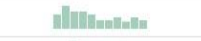 \\
\hline [1] the business intelligence reporting & $\square$ & 3600 & 110 & 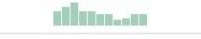 \\
\hline 『 microsoft business inielligence & $\square$ & 14800 & 320 & 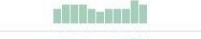 \\
\hline 田 is intelligence business & $\square$ & 450000 & 18100 & allilinuillill \\
\hline 圆 斿 busingss intelligence bi & Q & 5400 & 140 & 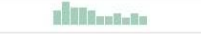 \\
\hline [1 2 businessintelligence pdf & $\square$ & 6600 & 210 & 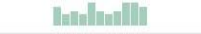 \\
\hline [I. th cognos business intelligence & $\square$ & 4400 & 140 & millinallinilin \\
\hline 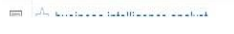 & 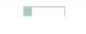 & $n \times n$ & « & 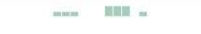 \\
\hline
\end{tabular}

Figure 5. Proposal for keywords related to "competitive intelligence" language: French, Territory: France assorted research estimated monthly - provided by Google Keyword Tool.

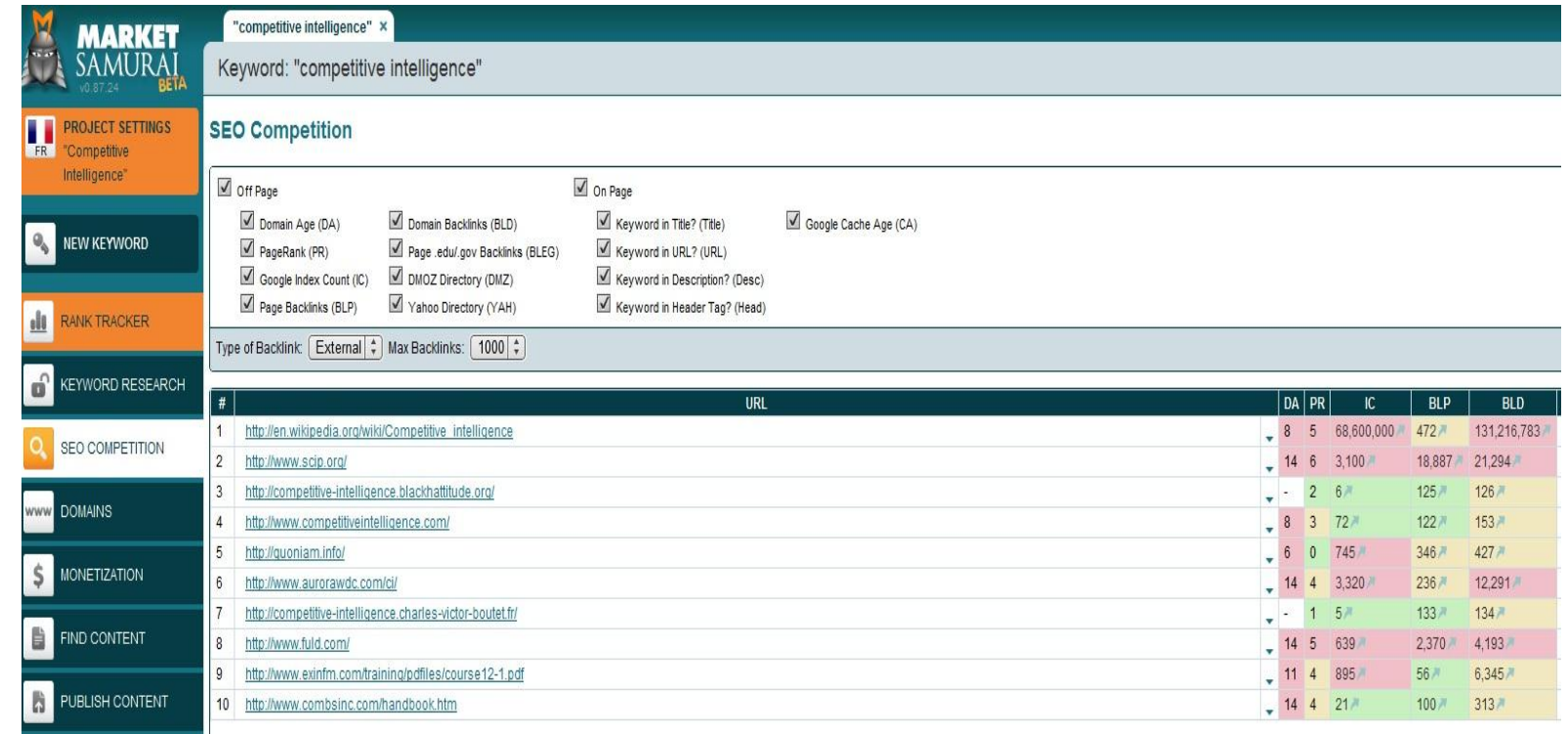

Figure 6. Top ten results for keyword "competitive intelligence" on google.fr French, established by the software market samurai on 14/02/2011.

\subsubsection{Massively disseminate information}

Web 2.0 allows anyone to create blogs hosted on dedicated platforms for this purpose. We can choose to disseminate information on our forums, wiki, weblogs, or third parties on our own media, in Figure 7, the screen capture tool "link farm evolution" which allowed us to create weblogs on 6149 third-party platforms: Web 2.0 allows the construction of territories potentially unlimited and to massively disseminate our information to get 


\section{Opinion Section}

better visibility, the mere existence of these territories, but also because Google will collect the information we have widely distributed among them.

Proof is that the top ten results on google.fr French language for the query "competitive intelligence", are three of our websites on 14/02/2011 as shown in Figure 6:

http://competitive-intelligence.blackhattitude.org is at rank 3, http://quoniam.info rank 5 and http://competitive-intelligence.charles-victor-

boutet.fr to rank 6 . We expand on this type of manoeuvre to the next (called SERP ${ }^{3}$ domination) which is a strategy of influence pay (infra,) since it can give legitimacy to whoever takes many good positions on a particular keyword since "we must find ways to understand issues related to influence strategies implemented by various public and private actors (including lobbying) and apply the techniques of persuasion and influence" (Mongereau, 2006).

\footnotetext{
3 SERP: (Search engine Result Pages) search results classified by search engines.
} 
Welcome to the LinkFarmEvolution. Here is a quick rundown of what's going on right now(sever time is 07:28):

- You have 2967 WPMU hosts to create blogs on.

- You have $\mathbf{5 4 6 3}$ Pligg hosts to put your links on.

- You also have $\mathbf{0}$ Google accounts with $\mathbf{0}$ Blogger blogs per account on average.

- Your network consists of 6149 blogs, of which $\mathbf{0}$ are not yet activated and $\mathbf{4 8}$ blogs have been marked as not working.

- You have funds to crack 1,764 CAPTCHAs (\$2.6460; Add funds: $5 \$$ Add funds )

Figure 7. Screenshot of the software "link farm evolution": we've created a virtual territory consisting of 6149 blogs that are both 6149 locations spread our information and as many sources by which Google will collect its information

\section{Information overload and speed}

"The constant growth of information internationally [...] is a problem which questions: how this information will be built, combined and processed" (Dou et al., 2003) a fortiori since the 2.0 many-tomany context allows a greater flow of information, obviously in number and in speed, as tools to facilitate the disclosure of more instantaneous while requiring less knowledge of computers have emerged (Weblogs, Twitter, Buzz ...). Indeed, since the first automation devices for establishing route information from one individual to another during the years 1940 (Rasse, 2005) until now, information is increasing in speed (up to microseconds for High Frequency Trading ${ }^{4}$ ) transmission.

The knowledge economy is an economy of speed: values are not stocks that are preserved in time, they decrease with the increasing speed of the process (Quoniam and Boutet, Loc. Cit.). To extract value from knowledge, then it must accelerate their use by the widest possible dissemination and at the same time, often precisely because of its dissemination, knowledge is socialized. That is to say, it becomes common heritage to competitors and potential users. It is the parable of the cathedral and the bazaar (Raymond, 2001) - in fact, the widely disseminated information is widely harvested. This synergy has a major impact on the cycle of EI), the face of this profusion, facilitated by the rapid development of Internet and its applications, [...] How to find,

\footnotetext{
${ }^{4}$ High Frequency Trading: an algorithmic trading subclass, based on short term trading. i.e. a scalping technique at the computer scale (micro-seconds).
}

organize, disseminate relevant information, that giving comparative advantage to the company? (Domenech et al., 2009). Although "Our culture may be less predisposed to such practices. Yet they are essential (Ibid.).

\subsection{Overload influence strategy}

The possibilities are a factor of 2.0 increase in the aforesaid information overload and it is possible, for who knows this and understands the fundamentals of the vertical model data display used by the vast majority of engines, to monopolize the space on a desired search term as shown in Figure 8: on the sales site eBay: The seller of many USB memory-sticks instead of using the less expensive Hollandaise auction system (a single announce for $\mathrm{N}$ times the same object), made the choice to pay $\mathrm{N}$ times cost of listing to occupy the first pages in search engines. 


\section{Opinion Section}

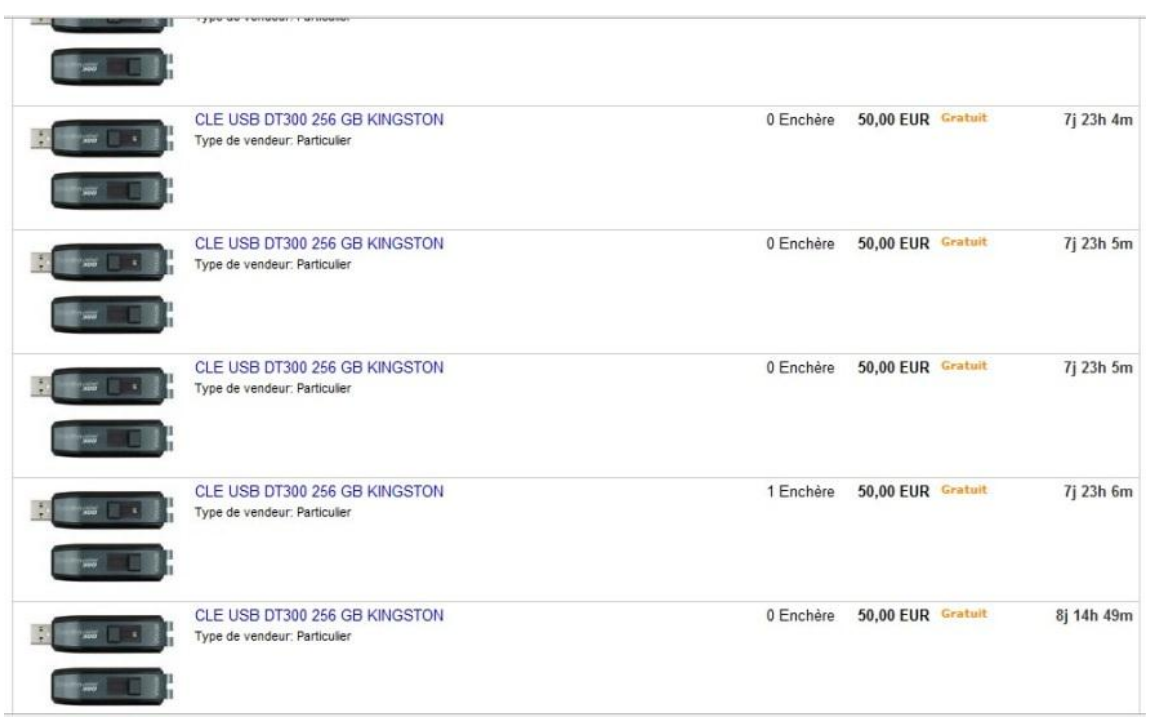

Figure 8. The same product occupies the front pages of research on research "USB", thus obscuring the competition in the eyes of potential customers.

As users see few results, and this "few" being situated among two or first three results pages (AT Internet Institute, 2009) (iProspect, 2006), a strategy of the screen where the information secret information (Ramonet, 2001) is implemented: we are seen and our competitors are overlooked de facto. Figure 8 also illustrates the principle of "SERP domination."

\subsection{Push-Pull}

RSS aggregators are a good example of glocalization data (supra.): the user can choose to unionize a site that provides information via a data flow (aka RSS) which allows him to obtain information in real time, using XML technology used to transmit the information content while the "presentation layer" will be managed by the RSS reader (Quoniam and Boutet, 2008).

During an information pull phase (first visit to a source of information and inclusion in RSS feeds), the user initiates a push by registering information: Information will now be to him and not vice versa. Instead of having to introduce robots which will regularly collect information for him, or worse, to navigate himself to the information, the user is in a position facilitating ingenium ${ }^{5}$ (Le Moigne, 2006), (Ciceron, 2003): From one end of this mental area to another, there are such distances we have never traveled $^{6}$ (Valery, 1992). Between folksonomy and information intensive push-pull through "active SEO", 2.0 aspect heavily impacts on the process of data collection.

\section{Conclusion}

The 2.0 aspect changes everything in terms of communication, information flow: the many-tomany, massive editing allows global impact, both in broadcasting as the harvesting, but also through the analysis tools needed to grip plethora of information that we have addressed in this article, therefore, the tools of 2.0 have a strong impact on the cycle of EI since are actually intended to handle the massive information. They offer attractive opportunities, particularly in terms of lobbying and are in fact, quite destined to occupy a major place in competitive intelligence in the future. It is possible to consider the cycle of EI as a new day cf. Figure 4, days that we will discuss extensively in the course of our future research.

\footnotetext{
${ }^{5}$ Ingenium: this strange faculty of the mind is to discern and relate to conjoin (Le Moigne, 2006)

${ }^{6}$ We see here a concept of mental area, concept on which de Rosnay and Schaer (2008) ask: what will happen when all humans will be interconnected?
} 


\section{Opinion Section}

\section{Bibliography}

AT Internet Institute. "Baromètre des moteurs Avril 2009," Avril 2009.

http://www.atinternet-institute.com/frfr/barometre-des-moteurs/barometre-desmoteurs-avril-2009/index-1-1-6-170.html.

Charles-Victor Boutet, et Samy Ben Amor. "Vers l'active SEO 2.0." Les cahiers du numérique 6, no. 1 (Juin 2010).

Cicéron, et A. Yon. L'Orateur. Belles Lettres, 2003.

Davenport, Thomas H., et Laurence Prusak. Working Knowledge: How Organizations Manage What They Know. 2 éd. Harvard Business School Press, 2000.

Dedijer, S. "Doing business in a changed world: The intelligence revolution and our planetary civilization." Competitive intelligence review (1999).

http://www3.interscience.wiley.com/journal/7 1006093/abstract.

Domenech, Sylvie, Manuel Marciaux, et Dominique Charnassé. "guide des bonnes pratiques en matière d'intelligence économique." SERVICE DE COORDINATION A L'INTELLIGENCE ECONOMIQUE, Février 2009. http://www.quoniam.info/competitiveintelligence/PDF/ebooks/Guide des bonnes pratiques_en matiere_d_IE.pdf.

Dou, Henri, Eric Boutin, et Luc Quoniam. "De la création es bases de données au développement des systèmes d'intelligence pour l'entreprise." ISDM, no. 8 (2003).

Elliott, Mark Alan. "Stigmergic Collaboration: A

Theoretical Framework for Mass

Collaboration." Melbourne: University of Melbourne, 2007.

HERRING, J. "Producing CTI that meets senior management's needs and expectations." SCIP Competitive Technical Intelligence Symposium (1997).
Heymann, Paul, Georgia Koutrika, et Hector Garcia-Molina. "Can social bookmarking improve web search?" Dans Proceedings of the international conference on Web search and web data mining, 195-206. WSDM '08. New York, NY, USA: ACM, 2008.

IProspect. "Search engin user behavior study" 2006.

http://www.iprospect.com/premiumPDFs/Whi tePaper_2006_SearchEngineUserBehavior.pd f.

Le Moigne, Jean-Louis. La théorie du système général - théorie de la modélisation. Les Classiques du Réseau Intelligence de la Complexité, 2006.

http://www.mcxapc.org/inserts/ouvrages/0609 tsgtm.pdf.

Luc Quoniam, et Charles-Victor Boutet. "Web 2.0, la révolution connectique." Document numérique 11, no. 1-2 (Décembre 2008).

Martin, Alban. L'âge de Peer: Quand le choix du gratuit rapporte gros. Village Mondial, 2006.

Mongereau, Roger. INTELLIGENCE ÉCONOMIQUE,RISQUES FINANCIERS ET STRATÉGIES DES ENTREPRISES. CONSEIL ECONOMIQUE ET SOCIAL, Septembre 26, 2006.

Ramonet, Ignacio. La Tyrannie de la communication. Gallimard, 2001.

Rasse, Paul. La rencontre des mondes : Diversité culturelle et communication. Armand Colin, 2005.

Raymond, Eric S. The Cathedral \& the Bazaar. Revised. O'Reilly, 2001.

Valéry, Paul. Introduction à la méthode de Léonard de Vinci. Gallimard, 1992.

Voss, J. "Tagging, folksonomy \& co-renaissance of manual indexing?" Arxiv preprint cs/0701072 (2007). http://arxiv.org/abs/cs.IR/0701072. 